\title{
Pollination efficiency of bumblebee, honeybee, and hawkmoth in kabocha squash, Cucurbita maxima, production in Kagoshima, Japan
}

\author{
Tsunashi Kamo $^{1} \cdot$ Aoi Nikkeshi ${ }^{1} \cdot$ Tomoya Tawaratsumida $^{2} \cdot$ Yoshihiro Tanaka $^{2} \cdot$ Shoko Nakamura $^{3,5} \cdot$ Shigeki Kishi $^{4}$
}

Received: 5 July 2021 / Accepted: 9 December 2021 / Published online: 1 February 2022

(c) The Author(s) 2022

\begin{abstract}
Kabocha squash, Cucurbita maxima Duchesne, in delayed-start culture is one of the major cultivation systems in southwestern Japan. Honeybee introduction or hand-pollination has been practiced in this crop system, but the species composition, abundance, and pollination efficiency of major pollinators remain unclear. In the current study, we investigated which insect(s) accomplish pollination of kabocha squash. Among the total visitations to female flowers, honeybees, mostly Apis mellifera L. (Hymenoptera: Apidae), dominated at $94.4 \%$ and $85.3 \%$ at the experimental field in 2019 and 2020, respectively, followed by the bumblebee Bombus diversus diversus Smith (Hymenoptera: Apidae) and the hummingbird hawkmoth Macroglossum pyrrhosticta Butler (Lepidoptera: Sphingidae). The number of pollen grains on the body surface of $B$. diversus diversus individuals was significantly greater than that on honeybees, such that a single visit by $B$. diversus diversus deposited 5-6 times more pollen grains on a stigma than a honeybee visit, meaning that the bumblebee is a more efficient pollinator at the individual level. However, visitations by numerous honeybees compensated for their lower individual efficiency and resulted in fruit set. In addition, we report for the first time that a lepidopteran can pollinate squash: our data indicate that pollen grains deposited by several visits of $M$. pyrrhosticta were likely to exceed the estimated minimum number of pollen grains required for fruit set. Our survey at the experimental field and at three private farms revealed that far more pollen than is required for fruit set was deposited on the stigmas by wild pollinators and wintering honeybees. These findings indicate that kabocha squash production in delayed-start culture in this region is practicable without pollination enhancement effort, such as honeybee introduction or hand-pollination.
\end{abstract}

Keywords Apis mellifera $\cdot$ Bombus diversus diversus $\cdot$ Cucurbita maxima $\cdot$ Macroglossum pyrrhosticta $\cdot$ Pollinator efficiency

Tsunashi Kamo

tkamo@affrc.go.jp

1 Institute for Agro-Environmental Sciences, National Agriculture and Food Research Organization, 3-1-3 Kannondai, Tsukuba, Ibaraki 305-8604, Japan

2 Kagoshima Prefectural Institute for Agricultural Development, 2200 Ohno, Kinpo-cho, Minamisatsuma, Kagoshima 899-3401, Japan

3 Forestry and Forest Products Research Institute, Forest Research and Management Organization, 1 Matsunosato, Tsukuba, Ibaraki 305-8687, Japan
4 Research Center for Agricultural Information Technology, National Agriculture and Food Research Organization, Kowa Nishishimbashi Building B, Nishishimbashi 2-14-1, Minato-ku, Tokyo 105-0003, Japan

5 Present Address: Forestry and Forest Products Research Institute, Forest Research and Management Organization, 1833-81 Todori, Hachioji 193-0843, Japan 


\section{Introduction}

Both wild insects and the domesticated European honeybee, Apis mellifera L. (Hymenoptera: Apidae) significantly contribute to the pollination of many crops (Breeze et al. 2011; Potts et al. 2010). Though recent studies have emphasized the importance of wild pollinators in the production of many crops (e.g., Garibaldi et al. 2013; Mallinger and Gratton 2015), the domesticated honeybee is still a reliable partner considering the fluctuating visitations and variable foraging traits of wild pollinators all over the world (Breeze et al. 2014; Decourtye et al. 2010). Thus, which bees, wild ones or domesticated honeybees, are better pollinators should be carefully evaluated, depending on the crops, localities, seasons, and species composition of wild pollinators (Potts et al. 2010).

Squash, Cucurbita spp., is a monoecious entomophilous plant that have hundreds of ovules in a female flower. Basically, the larger the number of pollinator visits to a female flower, the greater the probability of the fruiting becomes, and more seeds the fruit has (Artz and Nault 2011; McGrady et al. 2020; Vidal et al. 2010; Winsor et al. 2000). The fruit weight is positively correlated to the number of mature seeds (McGrady et al. 2020; Petersen et al. 2013). Aside from the squash bees, which are major pollinators of squash plants in origin, bumblebees and honeybees contribute to the production worldwide (Bomfim et al. 2016; Knapp and Osborne 2019).

Whereas pollination of squash crops is well studied in cool regions, few studies have reported the efficiency of pollinators or even lists of pollinating species in warm producing areas. According to the studies conducted in relatively cool locations, i.e., northeastern United States (Artz and Nault 2011; Vidal et al. 2010), southwestern Germany (Pfister et al. 2017), and highland in southwestern China (Xie and An 2014), bumblebees are found to be the most efficient pollinator of the plant per visit, that is, they deposit more pollen grains on a stigma per visit than other sympatric visitor insects. Similar results have been reported in the northern areas in Japan (Matsumoto and Yamazaki 2013; Nagamitsu et al. 2012; Nakamura et al. 2021).

Meanwhile, kabocha squash has been widely cultivated in Japan, from the southern to the northern part of the archipelago. Kagoshima prefecture, located in the southwestern part of Japan, has the second greatest amount of kabocha squash production following Hokkaido, located in northeast (Statistics Bureau, Ministry of Internal Affairs and Communications 2019). In contrast to the shorter growing season in Hokkaido, farmers in Kagoshima use the advantage of warm climate to produce kabocha squash in two cropping systems: semi-forcing culture (flowering in March-April) and delayed-start culture (September-October). These two systems have contrasting requirements for pollination in response to the commercial price. While farmers are willing to pay costs for hand-pollination to ship ahead of the rest of the producing areas in Japan to sell fruits at higher prices in semi-forcing culture, there is an increasing demand for saving labor and costs for pollination in delayed-start culture to survive price competition with other producing areas. However, farmers have continued to hand-pollinate the crop or to introduce honeybee colonies in their farms also in delayedstart culture, concerned about the yield reduction and quality deterioration of the crop. There is a possibility that pollination service provided by wild and domesticated pollinators is enough in that culture, but no studies have evaluated the availability of pollination service and the efficiency and contribution of pollinator species.

Our preliminary survey at our experimental field in Kagoshima demonstrated that the amount of kabocha squash production per area in delayed-start culture was satisfactory without pollination enhancement effort. Pollinators would be more active in delayed-start culture than in semi-forcing culture, because higher temperature enhances pollinators' activity (Hoehn et al. 2008). In addition, abundant wintering honeybees would be available in autumn, because many migratory beekeepers spend the autumn and winter months with their A. mellifera hives in Kagoshima (Sakai and Matsuka 1982).

To explore the possibility of producing kabocha squash without pollination enhancement efforts in delayed-start culture in warm Kagoshima prefecture, we first aimed to identify pollinator species and evaluate their pollination efficiency in the region in autumn. We monitored flower visitors and fruiting success for several locations and years, and counted the number of pollen grains on their body surfaces and those deposited on a stigma by a single visit. Then we estimated the minimum number of pollen grains required for fruit set by analyzing the relationship between the number of pollen grains deposited on a stigma and fruit set. Integrating those results, we discussed the contribution of visiting species and necessity for pollination enhancements.

\section{Method}

\section{Study sites}

Field observations and experiments were performed in the experimental field of the Kagoshima Prefectural Institute for Agricultural Development $\left(31.48^{\circ} \mathrm{N}, 130.34^{\circ} \mathrm{E}, 44 \mathrm{~m}\right.$ asl, hereafter "the experimental field") and at three private farms (Farms A-C; Table S1) in Kagoshima. The surrounding area of the experimental field was largely agricultural crops with relatively small secondary forests (Fig. S1). The surrounding areas of Farm A $\left(31.44^{\circ} \mathrm{N}, 130.33^{\circ} \mathrm{E}, 20 \mathrm{~m}\right.$ asl) and Farm 
$\mathrm{B}\left(31.51^{\circ} \mathrm{N}, 130.35^{\circ} \mathrm{E}, 10 \mathrm{~m}\right.$ asl $)$ were similar to that of the experimental field. Farm C $\left(31.54^{\circ} \mathrm{N}, 130.35^{\circ} \mathrm{E}, 20 \mathrm{~m}\right.$ asl) located near a mountainous area. The growing area for squash varied, from $180 \mathrm{~m}^{2}$ in the experimental field to 3000 $\mathrm{m}^{2}$ at Field A (Table S1).

Cucurbita maxima Duchesne 'Ebisu' was grown in the experimental field and Farm A, and farmers of Farms B and $\mathrm{C}$ grew 'Kuriyutaka'. Anthesis started in the middle to late September. Flowers bloomed before 05:00 h prior to dawn and withered by approximately $11: 30 \mathrm{~h}$ on the same day. Okra, Abelmoschus esculentus (L.) Moench (Malvales: Malvaceae), was the sole crop that bloomed simultaneously with kabocha squash in the experimental field. No domesticated pollinators, such as A. mellifera, were placed in any of the study fields. At Farms A and B, farmers performed hand-pollination, while at Farm $\mathrm{C}$, farmers relied on insects for pollination.

The 10-year mean monthly temperature ranged from $7.8^{\circ} \mathrm{C}$ in January to $28.3^{\circ} \mathrm{C}$ in August $\left(25.2{ }^{\circ} \mathrm{C}, 20.5^{\circ} \mathrm{C}\right.$, and $15.2^{\circ} \mathrm{C}$ in September, October, and November, respectively), and the mean annual precipitation was $2544 \mathrm{~mm}$, recorded at the nearest automated meteorological data acquisition point of the Japan Meteorological Agency (Minamisatsuma, Kagoshima; $31.42^{\circ} \mathrm{N}, 130.33^{\circ} \mathrm{E}, 9 \mathrm{~m}$ asl) from 2009 to 2018.

\section{Cultivation and management at the experimental field}

We grew squash in a plot $(30 \mathrm{~m} \times 6 \mathrm{~m})$ located in the experimental field. We seeded kabocha squash, C. maxima 'Ebisu', in pots on 19 August in 2019 and on 11 August in 2020, and transplanted 74 or 75 seedlings in a row at intervals of $0.4 \mathrm{~m}$ on 28 August 2019 and 25 August 2020 (Fig. S2). The plant tops were pinched on 9 October 2019 and 5 October 2020.

We applied fertilizers and controlled insect herbivores and pathogens following the standard practice described below, while weeds were controlled by hand. In $2019,0.9 \mathrm{~kg}$ each of nitrogen, phosphorus, and potassium was applied to the ridge $(30 \mathrm{~m} \times 0.5 \mathrm{~m})$ formed in the experimental plot $\left(180 \mathrm{~m}^{2}\right)$ before planting. The plot was side-dressed with $0.4 \mathrm{~kg}$ each of nitrogen and potassium after planting. We applied clothianidin (insecticide [I]) on 28 August, flubendiamide (I) and penthiopyrad (pesticide [P]) on 9 September, Bacillus thuringiensis formulations (I), oxolinic acid (P), and thiophanate-methyl (P) on 19 September, azoxystrobin (P), flonicamid (I), and flubendiamide (I) on 7 October, and quinoxaline $(\mathrm{P})$ on 25 October.

In $2020,1.35 \mathrm{~kg}$ each of nitrogen, phosphorus, and potassium was applied to the ridge $(30 \mathrm{~m} \times 0.5 \mathrm{~m})$ before planting, which was equivalent to $150 \%$ of the preceding year (based on the result of soil analysis). The plot was sidedressed in the same manner as the previous year. We applied clothianidin (I) on 25 August, copper sulfate (P) on 3 and 8 September, chlorothalonil (P) on 18 September, flutianil (P) on 25 September, and copper sulfate (P) and spinetoram (I) on 9 October, following the standard practices.

\section{Identification of flower-visiting species}

To identify flower-visiting species, we captured at least a few individuals from each taxonomic group based on the visual identification in the field. Individuals were captured during late September to early October in 2019 and 2020 in the experimental field, using a method in which a researcher moved the aperture of a 5- or 50-mL vial (depending on the size of insects) toward an insect that had entered a flower. On 26 and 29 September 2020, we specifically captured flowervisiting Macroglossum pyrrhosticta Butler (Lepidoptera: Sphingidae), which was not observed in the preceding year. Among the taxonomic groups, honeybees were captured exceptionally in large numbers ( $>100$ individuals per year), to identify species composition (European or Asian honeybees). Captured insects were morphologically identified in our laboratory.

\section{Monitoring frequency of flower visitations and fruiting success in open pollination}

In the experimental field (in 2019 and 2020) and Farms A-C (in 2020), the numbers of visiting insects, pollen grains deposited on stigmas, and fruiting success were monitored for 12-15 flowers in each year and location to understand the available amount of pollination service. For 4 to 6 consecutive days in each research year in every location, we selected two or three female flowers every day in each field and placed a video camera (Handycam HDRPJ675, Sony Corp., Tokyo, Japan) fixed on a tripod about $30 \mathrm{~cm}$ away from each flower, and videotaped the flowers from daybreak (approximately 06:00 h) until withering of the flower (approximately 11:30 h). From these video files, we classified every flower visitor into the following taxonomic groups: honeybee, Bombus diversus diversus Smith (Hymenoptera: Apidae), Campsomeriella annulata annulata (Fabricius) (Hymenoptera: Scoliidae), M. pyrrhosticta, small bee, or other, and calculated taxonomic composition.

To count the number of pollen grains deposited, the stigmas of these flowers were collected at approximately $24 \mathrm{~h}$ (in 2019) or $48 \mathrm{~h}$ (in 2020) after anthesis, which did not affect ovary growth. Suzuki (1969) reported that the time required for pollen-tube growth and fertilization in Cucurbita sp. is 3-5 and 9-11 h after pollination, respectively. To deal with the large stigmas under a microscope (SZ61; Olympus, Tokyo, Japan), we cut the stigmas into three portions without dyeing, and counted the pollen grains of $C$. 
maxima while continuously shifting the focusing distance. Fruit set of these flowers was checked 14 days after anthesis.

\section{Counting pollen grains on insects' body surfaces}

We counted the numbers of $C$. maxima pollen grains on the body surfaces (excluding pollen loads) of flower visitors captured on male and female flowers, following the experimental protocol of Nikkeshi et al. (2019). We captured 23 and 14 honeybees, and 9 and $4 B$. diversus diversus from female and male flowers, respectively, at Farm A on 20 September 2020. Each tube containing a captured insect was immediately put on ice in a cooler bag to quell its activity and prevent decomposition of the pollen loads. The insects were then taken to our laboratory and stored in the tubes at $-30^{\circ} \mathrm{C}$ in the freezer until pollen-counting analysis. After cutting away the insect's hind legs by using scissors to exclude pollen loads, each body sample was put into $0.4 \mathrm{M}$ sucrose solution and vortexed. We then counted the number of pollen grains in small drops of the solution under a microscope (SZ61), and calculated the total number of pollen grains attached on the individual's body surface.

\section{Evaluating pollination efficiency by a single visit}

To evaluate pollination efficiency of visitor species, we performed a field experiment to limit the number of visits at the experimental field in 2020. The number of pollen grains on a stigma and the probability of fruit set were compared among the following 6 pollination treatments: (1) no pollination (NP; 11 flowers), bagged with white polypropylene cloth as a negative control; (2) single visitation by M. pyrrhosticta (1-Mp; 22 flowers); (3) single visitation by a honeybee (1-HB; 22 flowers); (4) single visitation by $B$. diversus diversus (1-Bd; 19 flowers); (5) open-pollination (OP; 24 flowers); and (6) handpollination (HP; 10 flowers). For hand-pollination, an operator picked up a male flower, removed the petal off, and touched a stigma with the stripped anther. A male flower was used for one to three female flowers. This procedure was finished by 08:00 $\mathrm{h}$.

All of the flower buds except for the OP and HP treatments were covered with polypropylene cloth bags the previous day of the experiment to prevent unexpected visitations by insects before experiment. For the 1-Mp, 1-HB, and 1-Bd treatments, flowers were left opened on the morning of anthesis until we confirmed a single visit by one of the targeted species, and rebagged immediately after that. This experiment was performed during 06:00-08:00 $\mathrm{h}$ to avoid depletion of pollen in male flowers. Some of the flowers randomly selected from the OP treatment were concurrently used as targets for the monitoring of pollinators and fruiting success (see subsection "Monitoring frequency of flower visitations and fruiting success in open pollination" in Methods).
Pollen grains on the stigmas were counted in the same manner as described above by collecting stigmas $48 \mathrm{~h}$ after flowering, and fruiting success was assessed on 15 October 2020. We excluded flowers on plants that already had growing fruits from the assessment of fruiting success, because C. maxima plants often abort fruits when another fruit is growing (Stephenson 1981). In case the plant already had growing fruit(s), we counted the pollen grains deposited on the stigma, but then removed the ovary of those flowers. The numbers of flowers used for checking fruit set were 11, 13, $17,9,15$, and 10 for the NP, $1-\mathrm{Mp}, 1-\mathrm{HB}, 1-\mathrm{Bd}$, OP, and HP treatments.

\section{Relationship between the number of pollen grains on a stigma and yields}

To clarify the relationship between the number of pollen grains deposited on a stigma and resulting seed numbers and fruit weight, we used fruits that had developed from the flowers from which the stigmas were collected for counting deposited pollen grains. We harvested and weighed fruits on 13 November 2019 or 19 November 2020, and the numbers of mature seeds were counted afterwards. We limited the fruits to those grown in the experimental field because of the difference of growing conditions and cultivar used. Thus, 33 and 32 flowers were used for this experiment in 2019 and 2020, respectively.

\section{Statistical analysis}

To test whether the number of $C$. maxima pollen grains on the insect body surface differed significantly between major visitors (honeybees vs. $B$. diversus diversus) and between the individuals collected on female versus male flowers, we fitted generalized linear models (GLMs) assuming a Poisson distribution in which the response variable was the number of pollen grains and the explanatory variables were visitor species, flower sex, and the interaction effect. Tukey's HSD test was carried out for post hoc multiple comparisons.

To compare the number of pollen grains on a stigma among the six pollination treatments (i.e., NP, 1-Mp, 1-HB, 1-Bd, OP, and HP), we performed a non-parametric Mann-Whitney $U$ test for pairwise comparisons. Following Bonferroni correction, we set the threshold value to $p=0.05 / 15=0.0033$.

To compare the probability of fruiting success among the six treatments, we calculated the probability distribution of the fruiting success for each treatment using a Bayesian model. In the model, we assumed that the result of each treatment (i.e., the number of fruit set out of the total replicates) was caused by Bernoulli trials with the certain success probability. To fit a Baysian model, we ran 2000 iterations for each of four chains in Markov chain Monte 
Carlo sampling. We calculated the mean value and the $95 \%$ confidence interval (CI) of the estimated probability distribution of each treatment and compared them among the six treatments.

To test whether the fruiting success increased with the number of pollen grains on a stigma, we fitted a GLM to the data in which the response variable was fruiting success, assuming a binomial distribution, the link function was the logit, and the explanatory variable was the number of pollen grains on a stigma. The number of pollen grains at the inflection point on a fitted logistic curve, where the probability of fruiting success was 0.5 , was calculated from the estimated values of the best-fitting model.

We examined whether the number of mature seeds in a fruit increased with the number of pollen grains on a stigma. We fitted a generalized linear mixed model (GLMM) to the dataset in which the response variable was the number of mature seeds in a fruit, with Poisson distribution, the link function was the logarithm, the explanatory variable was the number of pollen grains on a stigma, and year was a random effect. To test whether the fresh weight of a fruit increased with the number of pollen grains on a stigma, we fitted a linear regression mixed model to the dataset, in which the response variable was the fresh weight of a fruit, the explanatory variable was the number of pollen grains on a stigma, and year was a random effect.

All statistical analyses were performed in R statistical software, version 4.0.4 (R Development Core Team 2021). We used the rstan package for data sampling when using the Markov chain Monte Carlo method in a Bayesian model (Stan Development Team 2020).

\section{Results}

\section{Flower-visitor species}

Morphological identification indicated that the flower visitors captured in the experimental field in the 2 years consisted of at least 16 species. The honeybees captured in 2019 (126 individuals) were identified as A. mellifera (107 individuals; 84.9\%) and Apis cerana japonica Radoszkowski (Hymenoptera: Apidae) (19 individuals; 15.1\%), and those captured in 2020 (113 individuals) were identified as A. mellifera (108 individuals; 95.6\%) and A. cerana japonica (5 individuals; $4.4 \%$ ). The other flower visitors were identified as Aulacophora nigripennis Motchulsky (Coleoptera: Chrysomelidae), Nitidulidae sp. (Coleoptera), Stomorhina obsoleta (Wiedemann) (Diptera: Calliphoridae), B. diversus diversus (Hymenoptera: Apidae), Lasioglossum mutilum (Vachal), Lasioglossum occidens (Smith) (Hymenoptera: Halictidae), C. annulata annulata, Megacampsomeris schulthessi (Betrem), Scolia decorata ventralis Smith 
(Hymenoptera: Scoliidae), Vespa analis Fabricius (Hymenoptera: Vespidae), Diaphania indica (Saunders) (Lepidoptera: Crambidae), Parnara guttata guttata (Bremer et Grey), Pelopidas mathias oberthuri Evans (Lepidoptera: Hesperiidae), and M. pyrrhosticta (Lepidoptera: Sphingidae).

\section{Frequency of flower visitations}

Although numbers varied among locations, video recording of all the flower-visiting insects showed that the mean number of total visits to a single female flower by any insect was more than 80 (Table 1). Most of the visits were made by honeybees, accounting for $94.4 \%$ and $85.3 \%$ at the experimental field in 2019 and 2020, respectively, and $85.4 \%$, $75.7 \%$, and $92.6 \%$ at Farms A, B, and C, respectively. In contrast, the percentages of flower visitations by the other insects, such as $B$. diversus diversus, small bees, $C$. annulata annulata, and $M$. pyrrhosticta, were inconsistent among years and locations.

\section{Fruiting success by open pollination}

For each stigma examined, more than 500 pollen grains on average were observed at any location (Table 1). Fruit sets ranged between $83.3 \%$ and $100 \%$. Six female flowers that received visitations only from honeybees and $M$.

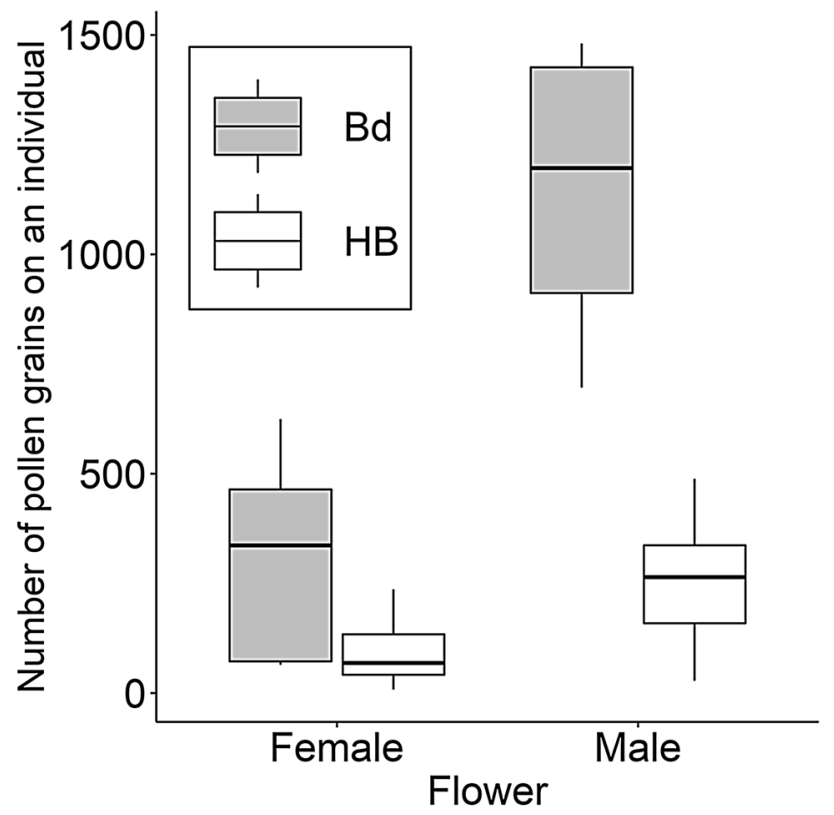

Fig. 1 The numbers of Cucurbita maxima pollen grains on the body surface of major insect visitors, Bombus diversus diversus (Bd) and honeybees (HB), captured on female and male flowers. The top, middle, and bottom lines of each box indicate the third, second (median), and first quartiles, respectively. The top and bottom end of whiskers indicate the maximum and minimum values between the third quartile +1.5 interquartile range (IQR) and the first $-1.5 \mathrm{IQR}$ pyrrhosticta set fruit (flower ID: 20F041, 20F043, 20F048, 20F050, 20F053, and 20F054 in Table S2).

\section{Number of pollen grains on insect body surfaces}

The number of $C$. maxima pollen grains on the body surfaces of insect visitors significantly differed among major species (GLM: $z=-42.51, p<0.0001 ;$ Fig. 1). Individuals captured on male flowers carried more pollen grains compared to those on female flowers $(z=53.18, p<0.0001)$. An interaction effect of the two factors was also detected $(z=-9.20$, $p<0.0001$ ). Thus, the number of pollen grains on $B$. diversus diversus individuals was significantly greater than those on honeybee individuals, and the number of pollen grains on an individual collected on a male flower was significantly greater than that on a female flower. Furthermore, the difference between the number of pollen grains on individuals captured on female and male flowers was large in $B$. diversus diversus compared to that of honeybees. While $26.9 \%$ (74 out of 275 individuals) of the captured honeybees possessed pollen loads, most of which consisted of C. maxima pollen grains, on their hind legs, none of the captured 18 B. diversus diversus possessed pollen loads (Kamo et al., unpublished data).

\section{Pollination efficiency of each species by single visits}

The numbers of pollen grains (mean $\pm \mathrm{SD}$ ) on a stigma in the six treatments were $0 \pm 0(\mathrm{NP}), 15.1 \pm 16.8(1-\mathrm{Mp})$, $29.3 \pm 48.6$ (1-HB), $170.1 \pm 114.7$ (1-Bd), $1058.0 \pm 305.5$ (OP), and 1507.2 \pm 173.0 (HP). Between any pair of the six treatments, the number of pollen grains on a stigma was significantly different (OP-HP: $W=25, p<0.0001$, OP-NP: $W=275, p<0.0001$, OP-1-HB: $W=550$, $p<0.0001$, OP-1-Bd: $W=475, p<0.0001, \mathrm{OP}-1-\mathrm{Mp}$ : $W=550, p<0.0001, \mathrm{HP}-\mathrm{NP}: W=110, p<0.0001$, HP-1-HB: $W=220, p<0.0001, \mathrm{HP}-1-\mathrm{Bd}: W=190$, $p<0.0001$, HP-1-Mp: $W=220, p<0.0001$, NP-1-HB: $W=22, p<0.0001, \mathrm{NP}-1-\mathrm{Bd}: W=0, p<0.0001, \mathrm{NP}-1-\mathrm{Mp}:$ $W=27.5, p<0.001,1-\mathrm{HB}-1-\mathrm{Bd}: W=46, p<0.0001$, 1-Bd-1-Mp: $W=388.5, p<0.0001)$, except for the pair of 1-HB and 1-Mp ( $W=284.5, p=0.316)$ (Fig. 2).

Because all of the R-hat convergence diagnostic values were within the range of 0.999 and 1.000 , we considered that all Bayesian models converged well. The estimated mean value of the fruiting success probability was 0.077 (95\% CI, 0.0019-0.270) in NP, 0.067 (0.0021-0.0229) in 1-Mp, $0.105(0.012-0.282)$ in $1-\mathrm{HB}, 0.725(0.444-0.934)$ in 1-Bd, $0.938(0.782-0.998)$ in OP, and $0.917(0.703-0.998)$ in HP (Fig. 3). Thus, the 95\% CIs of 1-Bd, OP, and HP widely overlapped, but were distinct from those of NP, 1-Mp, and 1-HB, which overlapped. 


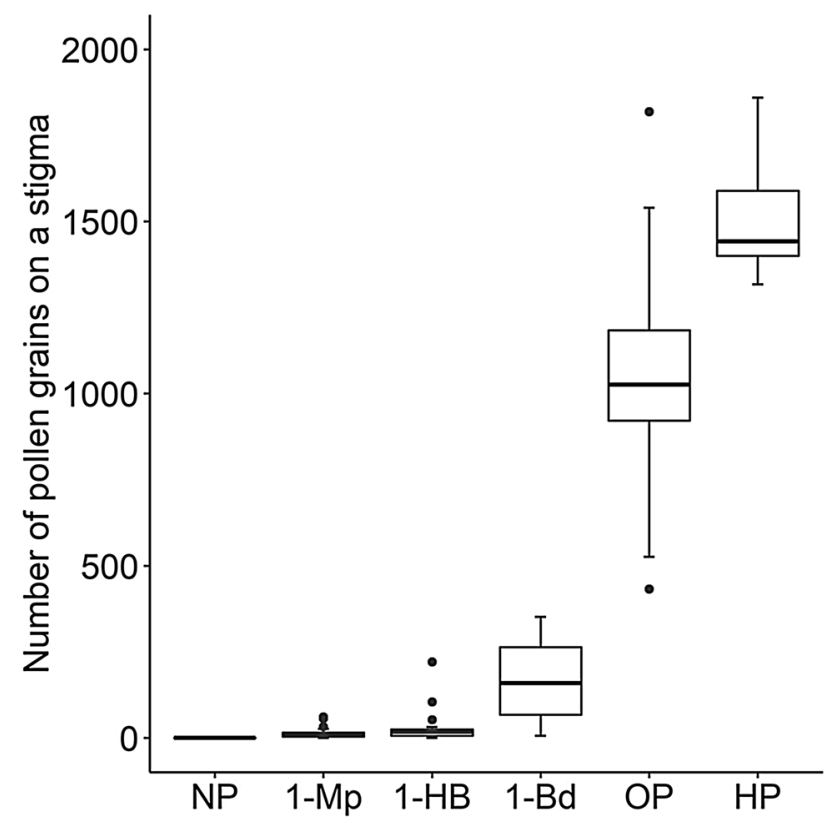

Fig. 2 The number of pollen grains deposited on a stigma of Cucurbita maxima 'Ebisu' in six pollination treatments: no pollination (NP); single visitation by Macroglossum pyrrhosticta (1-Mp); single visitation by honeybees (1-HB); single visitation by Bombus diversus diversus (1-Bd); open pollination ( $\mathrm{OP})$; and hand-pollination (HP). The top, middle, and bottom lines of each box indicate the third, second (median), and first quartiles, respectively. The top and bottom end of whiskers indicate the maximum and minimum values between the third quartile +1.5 interquartile range (IQR) and the first -1.5 IQR. Closed circles are outliers. A significant difference was detected between any pair of the six treatments (see text for details) except for the pair of $1-\mathrm{HB}$ and $1-\mathrm{Mp}$

\section{Relationship between the number of pollen grains deposited on stigmas and yields}

The success of fruit set increased with the increase in the number of the pollen grains on a stigma $(z=3.46$, $p=0.00055$; Fig. 4). The estimated values of the intercept and coefficient in the estimated logistic curve were -4.063 and 0.024 , such that the number of pollen grains at the inflection point of the curve was 167.7.

GLMM detected a significant effect of the number of pollen grains on the number of mature seeds in a fruit $(z=4.16$, $p<0.0001$, Fig. 5a). The coefficient value of the explanatory variable was 0.000114 , meaning that the number of mature seeds increases $\exp (0.000114)=1.000114$ times when the number of pollen grains deposited on a stigma increases by one. However, the fresh weight of a fruit did not significantly increase with the number of pollen grains deposited on a stigma $(t=-1.60, p=0.115$, Fig. $5 b)$.

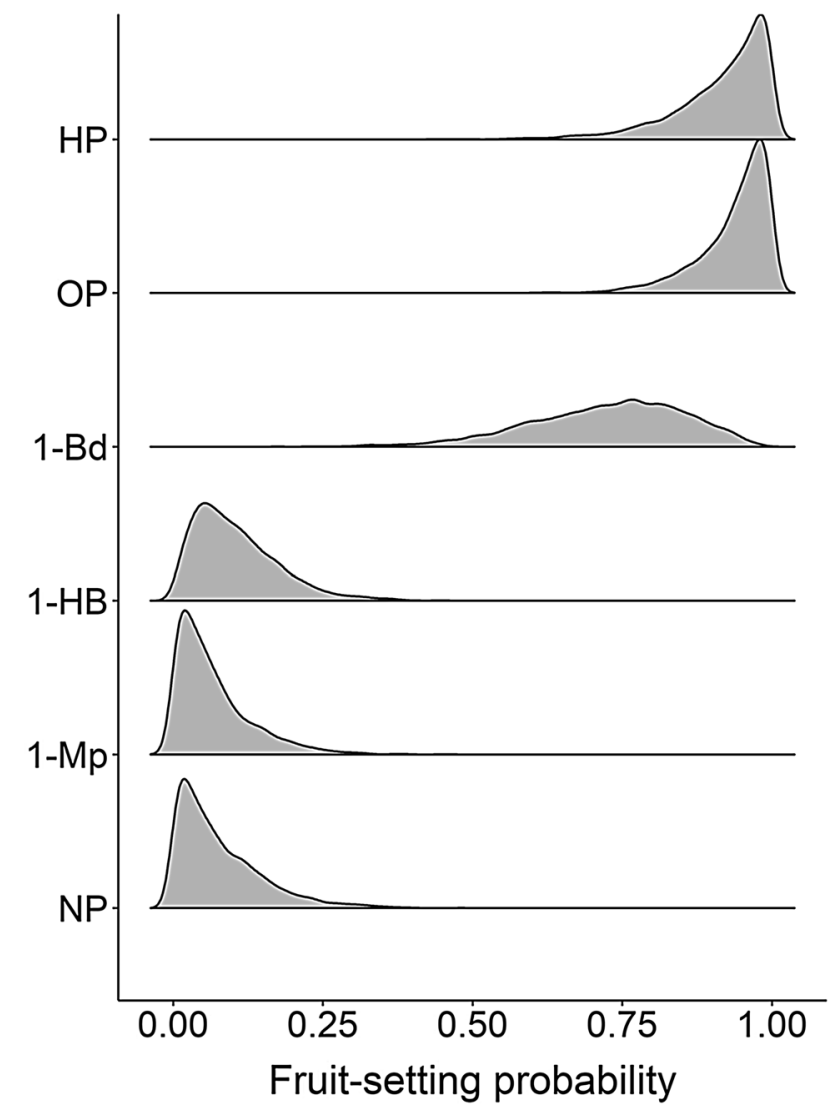

Fig. 3 Distribution of the probability density of fruit setting estimated by Baysian models of Cucurbita maxima 'Ebisu' in six pollination treatments: no pollination (NP); single visitation by Macroglossum pyrrhosticta (1-Mp); single visitation by honeybees (1-HB); single visitation by Bombus diversus diversus (1-Bd); open pollination (OP); and hand-pollination (HP)

\section{Behaviors of flower visitors}

Common behaviors of honeybees and a bumblebee in a female flower are presented in Supplementary Video 1. As shown in these images, in which two honeybee individuals (A. mellifera and A. cerana japonica, in order of appearance) were sucking nectar, the honeybees' bodies made inconsistent contact with the pistil. In contrast, $B$. diversus diversus, which visited the same flower later, moved clumsily inside the corolla, resulting in more contacts with the reproductive organs. In addition, a large amount of pollen was visible on the fuzzy body of the bumblebee.

Two different types of contact with a female flower by M. pyrrhosticta are presented in Supplementary Videos 2 and 3 . When this species sucks nectar with its extended proboscis, it makes few contacts with the flowers' reproductive organs (Supplementary Video 2). We also observed, however, that $M$. pyrrhosticta often held onto a stigma when sucking nectar, and the behavior is likely 
Fig. 4 Probability of fruit set of Cucurbita maxima 'Ebisu' when the given number of pollen grains is deposited on a stigma. Open circles indicate observed data and the dashed line indicates a fitted logistic curve



to involve depositing pollen on a stigma (Supplementary Video 3).

\section{Discussion}

The current study revealed that $B$. diversus diversus was the most efficient pollinator per visit in delayed-start culture of kabocha squash in Kagoshima, Japan. The number of pollen grains on individuals of this species was significantly greater than that on honeybee individuals. The average number of pollen grains deposited on a stigma by a single $B$. diversus diversus visit was also larger than that from a single honeybee visit or a single $M$. pyrrhosticta visit. In the pollination experiment, even a single visit by $B$. diversus diversus nearly achieved fruit set (success probability: 0.725 ), whereas visitation by a single honeybee or a single $M$. pyrrhosticta hardly achieved set fruit (success probability: 0.105 and 0.067 , respectively). Thus, this bumblebee pollinates far more efficiently than honeybees and the hawkmoth at the individual level. The bumblebee's excellent pervisit pollination efficiency is consistent with previous studies performed in other countries (Artz and Nault 2011; Pfister et al. 2017; Vidal et al. 2010; Xie and An 2014). Our field observations suggest that their large and hairy body and the clumsy movements in the flowers likely contribute to the pollination efficiency of bumblebees.

We confirmed that female flowers that were exclusively visited by honeybees or $M$. pyrrhosticta, less efficient pollinators than B. diversus diversus, could set fruit (Table S2). Taking account of the average minimum number of pollen grains required for fruit set (167.7) and the average number of pollen grains deposited during a single visit by a honeybee $(29.3 \pm 48.6)$, only six visitations by honeybees might meet the threshold number. Therefore, we conclude that honeybees were also effective pollinators for the kabocha squash at our experimental field. Artz and Nault (2011) reported a positive relationship between the number of visitations and the subsequent fruiting success of Cucurbita pepo L., for both European honeybee and the bumblebee Bombus impatiens Cresson, but under a low visitation rate the ratio of fruiting success was lower for flowers pollinated by honeybees compared to those pollinated by bumblebees. Thus, honeybees' low efficiency of pollination is compensated for by their large numbers, whereas the highly efficient pollination of bumblebees requires fewer visits to achieve fruit set.

Furthermore, our study is the first to indicate that a lepidopteran species, the hummingbird hawkmoth, M. pyrrhosticta, is likely to provide significant pollination service to Cucurbita spp. Although Bomfim et al. (2016) noted flower visitation to cucurbit crops by lepidopterans, their deposition of pollen on stigmas was thought to be little or none. In a study using Cucurbita andreana Naudin, the behavior of flower visitors was monitored and pollen grains attached on their body surfaces were counted (Ashworth and Galetto 2001); the authors concluded that Eudiopthis hyalinata Stoll. (Lepidoptera: Pyraustidae) only took nectar, without touching fertile whorls of the flower. In contrast, $M$. pyrrhosticta often landed on the reproducing organs of kabocha squash flowers instead of hovering while sucking nectar. This behavior might be due to the mismatch between the length of proboscis and the depth of flower (Cucurbita maxima have quite large flower compared to $C$. andreana; see Nakamura et al. 2021; Teppner 2004). Our results demonstrated that $M$. 

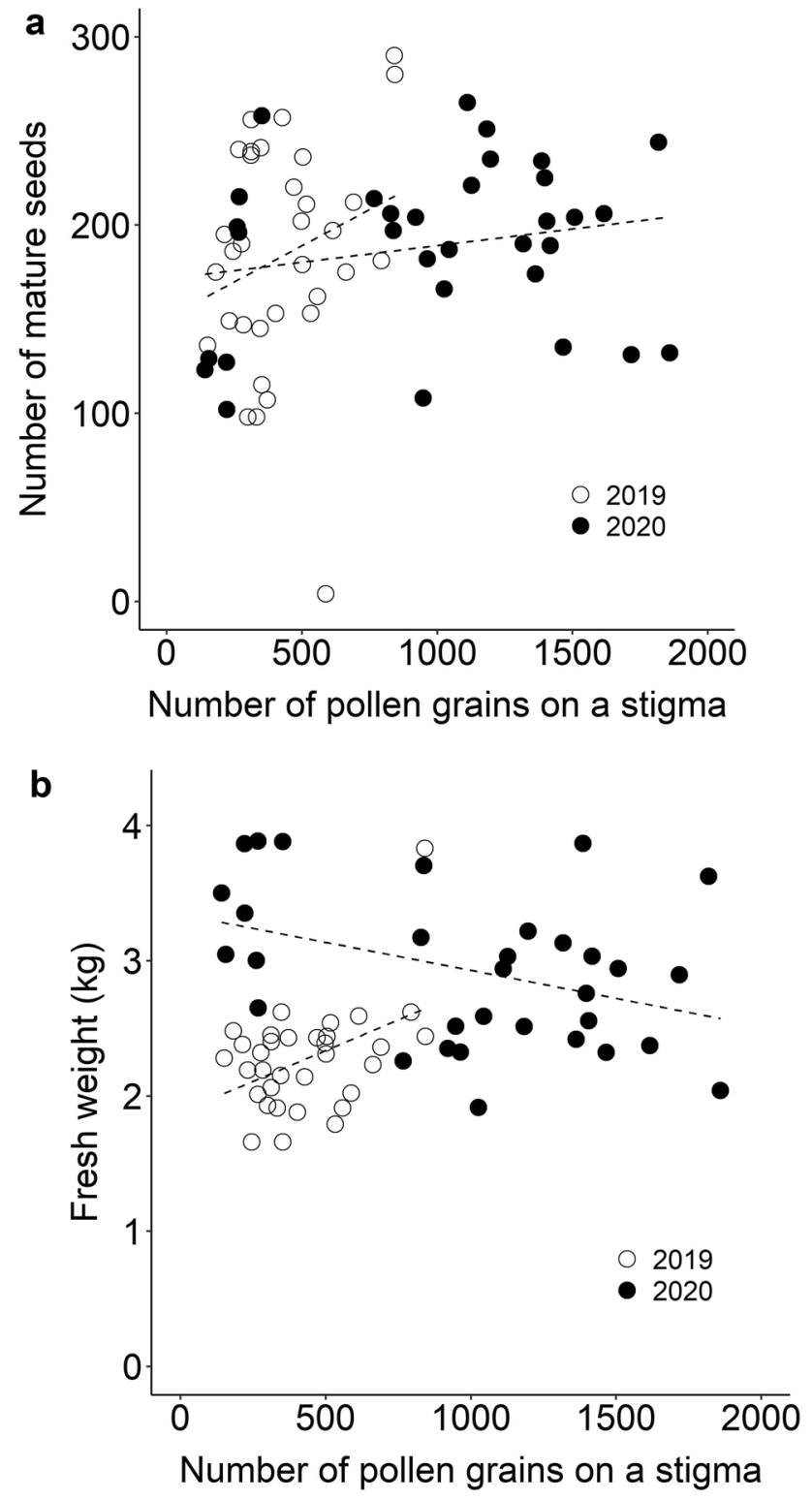

Fig. 5 The number of mature seeds developed in a Cucurbita maxima 'Ebisu' fruit (a) and the fruit weight (b) when the given number of pollen grains was deposited on the stigma. Open and closed circles indicate observed data in 2019 and 2020, respectively. Dashed lines show a linear regression line for each research year

pyrrhosticta could be a significant pollinator of squash at our study sites. On average, this species deposited 15.1 pollen grains per visit on a stigma. In 2020, this species visited each female flower 7.9-11.1 times in three of the four study sites. Therefore, the minimum number of pollen grains required for fruiting success, 167.7 , was potentially exceeded by $M$. pyrrhosticta visitations. The genus Macroglossum is diurnal or crepuscular (Kendrick 2010), which suits the flowering hour of Cucurbita spp. However, the contribution of M. pyrrhosticta to total squash pollination in this region would be relatively limited due to its lower per-visit efficiency and its smaller and fluctuating population (no individual was recorded in the experimental field in 2019). Further detailed studies may reveal other overlooked relationships between lepidopterans and cucurbit crops.

Although there should be clear species differences in pollination ability among pollinators, the number of pollen grains deposited during a single visit could depend on multiple factors. The numbers of pollen grains deposited during a single bumblebee or honeybee visit in our study are comparable with those reported by Xie and An (2014) (bumblebees, 14-604; honeybees, 0-12), but much smaller than those reported by Pfister et al. (2017) (Bombus terrestris L., mean 3369; A. mellifera, 582). These large differences might be partially due to the spatial arrangements of flowers in the field. At our intensively managed study site, like other small-scale kabocha squash fields in Japan, vines are arranged to grow in one direction. This results in spatial separation of flower sexes in two lines, because female flowers tend to bloom near the tip of a vine and male flowers clump at the base. In addition to field management, differences in pollinator density, sex ratio of flowers, and environmental conditions also could have affected the results (McGrady et al. 2020).

The estimated threshold number of pollen grains needed for fruit set, 167.7, is comparable with those reported for $C$. pepo, with reported estimates of 70 and 174 grains (Artz and Nault 2011; Vidal et al. 2010). However, our estimate is much less than the approximately 500 grains estimated for C. maxima 'Hokkaido' (Pfister et al. 2017). Several factors, such as differences in species and temperature, might explain this difference (Pfister et al. 2017).

We investigated whether additional visitations by pollinators over the minimum threshold for fruit set are necessary for plants to produce kabocha squash fruit with higher economic value. As the number of pollen grains deposited on a stigma increased, that of mature seeds also increased. No correlation was detected between the number of pollen grains and the fresh weight of the fruit, however, as opposite trends were noted in the two research years. In a previous study, Nicodemo et al. (2009) reported an inconstant relationship between visitation number by $A$. mellifera to a female flower of $C$. maxima and fruit weight, but the number of visits to a female flower is not always proportional to the number of pollen grains deposited on the stigma. It might be necessary, therefore, to obtain more data in multiple years for more accurate analysis of the relationship between the number of pollen grains and the fresh weight of fruit. However, farmers in this region aim to produce kabocha squash fruit of more than $0.8 \mathrm{~kg}$ fresh weight (minimum marketable size) and ideally $2.5 \mathrm{~kg}$ fresh weight (suitable size for a standard box for six fruits). Given that the fresh weight of all the fruit produced in our pollination experiment far exceeded 
$0.8 \mathrm{~kg}$, pollen deposition above the level of the minimum requirement for fruit set would not necessarily be required for kabocha squash production.

In addition to the experimental field, we confirmed that the female flowers of $C$. maxima received pollen sufficient for fruit set in three private farms. Nevertheless, hand-pollination is in practice in two of these farms. Considering the aging farmer population in Japan (Supaporn et al. 2012), it is vital to clarify the agricultural procedures that can be omitted by making the best use of ecosystem services. Fortunately, the warm temperature from mid-September to early October is suitable for active foraging by flower visitors. In addition, wintering honeybees are abundant in this region during the flowering season. We therefore surmise that farmers in Kagoshima prefecture could depend on pollination service in the delayed-start culture of kabocha squash.

In consistent with some reports on B. impatiens (Brochu et al. 2020; Treanore et al. 2019), the most efficient pollinator in the current study, $B$. diversus diversus, seemed to forage for nectar and might not willingly collect pollen on squash flowers. Planting flowers that provide favorable pollen near the crop may enlarge and stabilize the bumblebee population, and consequently may get the bumblebee to increase visits to squash flowers (Albrecht et al. 2021; Feltham et al. 2015). Our experimental approach for evaluating pollination services, possibly coupled with other attractant flowers in adjacent to the crop fields, is expected to contribute to alleviating farmers' concern for the pollination shortage, reducing labor costs for hand-pollination and achieving environmentally sustainable crop production.

Supplementary Information The online version contains supplementary material available at https://doi.org/10.1007/s13355-021-00766-2.

Acknowledgements We appreciate the kind cooperation of Dr. Norikuni Kumano (Obihiro University of Agriculture and Veterinary Medicine) and Dr. Soichi Kugimiya and Dr. Katsuyuki Kohno (National Agriculture and Food Research Organization) in the field experiments. We are grateful to Mr. Ken-ichi Ohkubo (Kagoshima Prefectural Institute for Agricultural Development) for cultivating kabocha squash at the study site. We thank the kabocha squash farmers for their kind cooperation. The technical assistance of Mr. Ryohei Hoshino is also greatly acknowledged. This work was supported financially by the Ministry of Agriculture, Forestry and Fisheries, Japan, through a research project entitled "Monitoring and enhancement of pollinators for crop production".

Open Access This article is licensed under a Creative Commons Attribution 4.0 International License, which permits use, sharing, adaptation, distribution and reproduction in any medium or format, as long as you give appropriate credit to the original author(s) and the source, provide a link to the Creative Commons licence, and indicate if changes were made. The images or other third party material in this article are included in the article's Creative Commons licence, unless indicated otherwise in a credit line to the material. If material is not included in the article's Creative Commons licence and your intended use is not permitted by statutory regulation or exceeds the permitted use, you will need to obtain permission directly from the copyright holder. To view a copy of this licence, visit http://creativecommons.org/licenses/by/4.0/.

\section{References}

Albrecht M, Kleijn D, Williams NM, Tschumi M, Blaauw BR, Bommarco R et al (2021) The effectiveness of flower strips and hedgerows on pest control, pollination services and crop yield: a quantitative synthesis. Ecol Lett 23:1488-1498. https://doi.org/ 10.1111/ele. 13576

Artz DR, Nault BA (2011) Performance of Apis mellifera, Bombus impatiens, and Peponapis pruinosa (Hymenoptera: Apidae) as pollinators of pumpkin. J Econ Entomol 104:1153-1161. https:// doi.org/10.1603/EC10431

Ashworth L, Galetto L (2001) Pollinators and reproductive success of the wild cucurbit Cucurbita maxima ssp. andreana (Cucurbitaceae). Plant Biol 3:398-404. https://doi.org/10. 1055/s-2001-16451

Bomfim IGA, Freitas BM, Arãgao FAS, Walter SA (2016) Pollination in cucurbit crops. In: Pessarakli M (ed) Handbook of cucurbits: growth, cultural practices, and physiology. CRC Press, Boca Raton, pp 181-200

Breeze TD, Bailey AP, Balcombe KG, Potts SG (2011) Pollination services in the UK: how important are honeybees? Agric Ecosyst Environ 142:137-143. https://doi.org/10.1016/j.agee.2011.03.020

Breeze TD, Vaissière BE, Bommarco R, Petanidou T, Seraphides N, Kozák L et al (2014) Agricultural policies exacerbate honeybee pollination service supply-demand mismatches across Europe. PLoS ONE 9:e82996. https://doi.org/10.1371/journal.pone.00829 96

Brochu KK, van Dyke MT, Milano NJ, Petersen JD, McArt SH, Nault BA et al (2020) Pollen defenses negatively impact foraging and fitness in a generalist bee (Bombus impatiens: Apidae). Sci Rep 10:3112. https://doi.org/10.1038/s41598-020-58274-2

Decourtye A, Mader E, Desneux N (2010) Landscape enhancement of floral resources for honey bees in agro-ecosystems. Apidologie 41:264-277. https://doi.org/10.1051/apido/2010024

Feltham H, Park K, Minderman J, Goulson D (2015) Experimental evidence that wildflower strips increase pollinator visits to crops. Ecol Evol 5:3523-3530. https://doi.org/10.1002/ece3.1444

Garibaldi LA, Steffan-Dewenter I, Winfree R, Aizen MA, Bommarco R, Cunningham SA et al (2013) Wild pollinators enhance fruit set of crops regardless of honey bee abundance. Science 339:16081611. https://doi.org/10.1126/science. 1230200

Hoehn P, Tscharntke T, Tylianakis JM, Steffan-Dewenter I (2008) Functional group diversity of bee pollinators increases crop yield. Proc R Soc B 275:2283-2291. https://doi.org/10.1098/rspb.2008. 0405

Kendrick RC (2010) The genus Macroglossum Scopoli 1777 (Lepidoptera: Sphingidae, Macroglossinae) in Hong Kong. Hong Kong Entomol Bull 2:13-21. http://hkentsoc.org/bulletin/HKEB2(1) Macroglossum_kendrick.pdf. Accessed 18 Mar 2021

Knapp JL, Osborne JL (2019) Cucurbits as a model system for crop pollination management. J Poll Ecol 25:89-102. https://doi.org/ 10.26786/1920-7603(2019)535

Mallinger RE, Gratton C (2015) Species richness of wild bees, but not the use of managed honeybees, increases fruit set of a pollinatordependent crop. J Appl Ecol 52:323-330. https://doi.org/10.1111/ 1365-2664.12377

Matsumoto T, Yamazaki K (2013) Distance from migratory honey bee apiary effects on community of insects visiting flowers of pumpkin. Bull Insectol 66:103-108 
McGrady CM, Troyer R, Fleischer SJ (2020) Wild bee visitation rates exceed pollination thresholds in commercial Cucurbita agroecosystems. J Econ Entomol 113:562-574. https://doi.org/10.1093/ jee/toz295

Nagamitsu T, Tsukuba S, Ushirokita F, Konno Y (2012) Foraging habitats and floral resource use by colonies of long- and short-tongued bumble bee species in an agricultural landscape with kabocha squash fields. Appl Entomol Zool 47:181-190. https://doi.org/10. 1007/s13355-012-0106-x

Nakamura S, Taki H, Konno Y (2021) Diurnal dynamics of nectar secretion in Cucurbita maxima Duch: implications for effective pollen transfer by Japanese wild pollinators. Jpn Agric Res Q 55:323-331. https://doi.org/10.6090/jarq.55.323

Nicodemo D, Couto RHN, Malheiros EB, De Jong D (2009) Honey bee as an effective pollinating agent of pumpkin. Sci Agric 66:476480. https://doi.org/10.1590/S0103-90162009000400007

Nikkeshi A, Inoue H, Arai T, Kishi S, Kamo T (2019) The bumblebee Bombus ardens ardens (Hymenoptera: Apidae) is the most important pollinator of Oriental persimmon, Diospyros kaki (Ericales: Ebenaceae), in Hiroshima, Japan. Appl Entomol Zool 54:409419. https://doi.org/10.1007/s13355-019-00637-x

Petersen JD, Reiners S, Nault BA (2013) Pollination services provided by bees in pumpkin fields supplemented with either Apis mellifera or Bombus impatiens or not supplemented. PLoS ONE 8:e69819. https://doi.org/10.1371/journal.pone.0069819

Pfister SC, Eckerter PW, Schirmel J, Cresswell JE, Entling MH (2017) Sensitivity of commercial pumpkin yield to potential decline among different groups of pollinating bees. R Soc Open Sci 4:170102. https://doi.org/10.1098/rsos.170102

Potts SG, Biesmeijer JC, Kremen C, Neumann P, Schweiger O, Kunin WE (2010) Global pollinator declines: trends, impacts and drivers. Trends Ecol Evol 25:345-353. https://doi.org/10.1016/j.tree. 2010.01.007

R Development Core Team (2021) R: a language and environment for statistical computing. R Foundation for Statistical Computing, Vienna, Austria. http://www.R-project.org. Accessed 18 Jan 2022

Sakai T, Matsuka M (1982) Beekeeping and honey resources in Japan. Bee World 63:63-71

Stan Development Team (2020) RStan: the R interface to Stan. R package version 2.21.1. https://mc-stan.org. Accessed 18 Jan 2022

Statistics Bureau, Ministry of Internal Affairs and Communications (2019) The e-Stat (a portal site for Japanese Government
Statistics) of the Statistics Bureau, Ministry of Internal Affairs and Communications. Table f005-30-059 (In Japanese). https:// www.e-stat.go.jp/stat-search/files?page $=1 \&$ layout=datalist $\&$ toukei $=00500215 \&$ tstat $=000001013427 \&$ cycle $=7 \&$ year $=20180$ $\&$ month $=0 \&$ tclass $1=000001032286 \&$ tclass $2=000001032933 \&$ tclass $3=000001135323$. Accessed 6 March 2020

Stephenson AG (1981) Flower and fruit abortion: proximate causes and ultimate functions. Ann Rev Ecol Syst 12:253-279

Supaporn P, Kobayashi T, Pongsagorn P (2012) Aspects of the aging farming population and food security in agriculture for Thailand and Japan. Int J Environ Rural Dev 3:102-107. http://iserd.net/ ijerd31/31102.pdf. Accessed 3 Feb 2021

Suzuki E (1969) Studies on the fruit development of green house melon (Cucumis melo L.). I. On the relation between the shape of stigma and the number of seeds, and on the pollen tube development and the hour of fertilization. J Jpn Soc Hortic Sci 38:36-41. https:// doi.org/10.2503/jjshs.38.36 (In Japanese with English abstract)

Teppner H (2004) Notes on Lagenaria and Cucurbita (Cucurbitaceae) -Review and new contributions. Phyton 44:245-308

Treanore ED, Vaudo AD, Grozinger CM, Fleischer SJ (2019) Examining the nutritional value and effects of different floral resources in pumpkin agroecosystems on Bombus impatiens worker physiology. Apidologie 50:542-552. https://doi.org/10.1007/ s13592-019-00668-x

Vidal MDG, De Jong D, Wien HC, Morse RA (2010) Pollination and fruit set in pumpkin (Cucurbita pepo) by honey bees. Braz J Bot 33:107-113. https://doi.org/10.1590/S0100-84042010000100010

Walters SA, Taylor BH (2006) Effects of honey bee pollination on pumpkin fruit and seed yield. HortScience 41:370-373. https:// doi.org/10.21273/HORTSCI.41.2.370

Winsor JA, Peretz S, Stephenson AG (2000) Pollen competition in a natural population of Cucurbita foetidissima (Cucurbitaceae). Amer J Bot 87:527-532. https://doi.org/10.2307/2656596

Xie Z, An J (2014) The effects of landscape on bumblebees to ensure crop pollination in the highland agricultural ecosystems in China. J Appl Entomol 138:555-565. https://doi.org/10.1111/jen.12122

Publisher's Note Springer Nature remains neutral with regard to jurisdictional claims in published maps and institutional affiliations. 